\title{
IMPACT OF INCARCERATION ON RATES OF METHADONE USE IN A COMMUNITY RECRUITED COHORT OF INJECTION DRUG USERS
}

\author{
John D. Koehn ${ }^{1}$, Paxton Bach ${ }^{1,2}$, Kanna Hayashi ${ }^{1,2}$, Paul Nguyen ${ }^{1}$, Thomas Kerr ${ }^{1,2}$, MJ \\ Milloy $^{1,2}$, Launette Rieb ${ }^{1,3}$, and Evan Wood ${ }^{1,2}$ \\ ${ }^{1}$ British Columbia Centre for Excellence in HIV/AIDS, St. Paul's Hospital \\ ${ }^{2}$ Department of Medicine, University of British Columbia \\ ${ }^{3}$ Department of Family Practice, University of British Columbia
}

\section{Abstract}

Background-Despite barriers to its use in many settings, opioid agonist therapy with methadone has become the standard of care for treating opioid (e.g. heroin) use disorder. Since people with opioid use disorders have an increased incidence of incarceration, we undertook the present study to evaluate the association between incarceration and methadone maintenance therapy among a cohort of injection drug users in a Canadian setting.

Methods-A cohort of people who inject drugs were prospectively followed between May 1996 and May 2013 in Vancouver, Canada. We investigated the relationship between recent incarceration and methadone use using multivariate generalized estimating equations (GEE) logistic regression analysis.

Results-Overall, 2758 individuals were recruited during the study period and followed for a median of 64 (interquartile range: 23 - 106) months. After adjusting for various potential confounders in the multivariate GEE model, being incarcerated remained independently associated with a lower likelihood of having received methadone treatment (Adjusted Odds Ratio: 0.87, 95\% confidence interval: $0.81-0.93)$.

Conclusions-Our study demonstrates that incarceration was independently associated with a significantly lower likelihood of being on methadone. Given the role of methadone in reducing the harms of heroin use, including drug acquisitive crime and recidivism, these data suggest a need to scale-up methadone provision for incarcerated injection drug users.

(C) 2015 Published by Elsevier Ltd.

Send correspondence to: Evan Wood, MD, PhD, ABIM, FRCPC, Professor of Medicine, Division of AIDS, Canada Research Chair in Inner City Medicine, University of British Columbia, Director, Urban Health Research Initiative, BC Centre for Excellence in HIV/ AIDS, Phone: 604-682-2344 X 66373, uhri-ew@cfenet.ubc.ca.

Publisher's Disclaimer: This is a PDF file of an unedited manuscript that has been accepted for publication. As a service to our customers we are providing this early version of the manuscript. The manuscript will undergo copyediting, typesetting, and review of the resulting proof before it is published in its final citable form. Please note that during the production process errors may be discovered which could affect the content, and all legal disclaimers that apply to the journal pertain. 


\section{Keywords}

Methadone maintenance therapy; Injection drug use; Incarceration

\section{Introduction}

Although only a fraction of patients with a diagnosed substance use disorder identify opioids as their drug of choice, a greater proportion of these individuals will suffer severe health consequences. This increased risk is particularly pronounced in individuals who use heroin. Heroin use and increased access to prescribed opioids has also led to an epidemic of overdose deaths in North America (Fischer, Jones, \& Rehm, 2013). Substantial public health and social issues are associated with opioid addiction, particularly in urban centers. These include involvement in the sex trade, drug acquisition crime, loss of child custody, and unstable housing. Sadly, despite increased efforts to apply a medical approach to the treatment of opioid addiction, stigmatization and criminalization of affected individuals abound (Wolfe, Carrieri, \& Shepard, 2010).

Barriers to opioid agonist therapy internationally include access-limiting legislation, costs associated with the medication, and negative public and patient opinion about treatments such as methadone. Individual factors, such as residence and drug-using behaviors, have also been identified as barriers to care (Callon et al., 2006). Limiting timely access to methadone defies strong evidence demonstrating its record for decreasing illicit opioid use as well as decreasing HIV infection rates as substantiated by its position on the World Health Organization's List of Essential Medicines (Herget, 2005; MacArthur et al., 2012; Mattick, Breen, Kimber, \& Davoli, 2009).

Methadone for the treatment of incarcerated individuals with opioid use disorders has been shown to decrease the risk of contracting viral hepatitis, decrease HIV risk behaviors and reduce rates of recidivism (Bukten et al., 2011; Hedrich et al., 2012; Werb et al., 2008). Unfortunately, the criminal justice system is often not optimized to address the addiction treatment needs of high-risk patients. To better understand this gulf in practice, the present study was conducted to examine the relationship between incarceration and engagement in methadone maintenance treatment among individuals with a history of injection drug use.

\section{Methods}

\subsection{Study design}

Beginning in May 1996, individuals who had injected illicit drugs in the past month were recruited into the Vancouver Injection Drug Users Study (VIDUS), a prospective cohort study that has been described in detail previously (Miller et al., 2002; Tyndall et al., 2003; Wood et al., 2003). Since 2005, people who were HIV-positive at baseline or during the study were subsequently followed through a sister study known as the AIDS Care Cohort to Evaluate Access to Survival Services (ACCESS). With exception to parameters related to HIV infection, both studies used essentially identical recruitment and follow-up procedures to allow for combined analyses. 


\subsection{Participants}

Participants of the studies were 18 years of age or older and resided in the greater Vancouver region. All participants provided written informed consent. Participants were given a stipend $(\$ 20 \mathrm{CDN})$ at each study visit for their time and transportation. The study was approved by the University of British Columbia/Providence Healthcare Research Ethics Board.

\subsection{Measures}

At baseline and semianually thereafter, participants completed an interviewer-administered questionnaire that elicited a range of data, including those on demographic characteristics, injection and non-injection drug use, and engagement in addiction treatment. In addition, venous blood samples were drawn at each visit and tested for HIV and hepatitis C Virus $(\mathrm{HCV})$ antibodies. All participants had private interviews and were offered both pre- and post-test counseling with trained nurses.

\subsection{Analysis}

The present analyses considered all individuals with a history of injection drug use who were enrolled between May 1996 and May 2013. Our primary outcome of interest was participation in the methadone treatment program in the past 6 months. Our primary independent variable of interest was recent incarceration, defined as being in detention (under 19 years of age), prison ( 2 years or more) or jail ( 2 years less than a day or under) in the past 6 months.

To examine the relationship between methadone treatment use and recent incarceration we considered several demographic and behavioral explanatory variables that may act as confounders. The secondary variables included: age; gender (female vs. male); ethnicity (Caucasian vs. other); injection heroin use ( $\geq$ daily vs. $<$ daily); injection cocaine use ( $\geq$ daily vs. < daily); crack cocaine smoking ( $\geq$ daily vs. < daily); HIV serostatus (positive vs. negative); involvement in sex work, defined as exchanging sex for money, food, drugs, shelter or other commodites (yes vs. no); currently living in unstable housing, defined as as living in a single room occupancy hotel, transitional living arrangements, or homelessness (Spittal et al., 2002). Unless specified, all behavioral variables refer to activities in the past 6 months.

Since the analyses included serial measures for each participant, we used generalized estimating equations (GEE) with the logit link function to assess the independent association of recent incarceration with participation in the methadone treatment program throughout the study period. The GEE methods provided standard errors adjusted by multiple observations per person using an exchangeable correlation structure (Liange \& Zeger, 1986). As a first step, variables were examined in bivariate GEE analyses. Then, to fit the multivariate confounding model for the variable of interest, we employed a conservative model selection approach (Maldonado \& Greenland, 1993). Specifically, we included all potential confounders (where $\mathrm{p}<0.05$ in the bivariate analyses) in the full multivariate model and used a stepwise approach to fit a series of reduced models. After comparing the value of the coefficient associated with the main independent variable of interest in the full model to 
the value of the coefficient in each of the reduced models, we dropped the secondary variable associated with the smallest relative change. We continued this iterative process until the minimum change exceeded 5\%. Remaining variables were considered confounders in the multivariate analysis. All statistical analyses were performed using the SAS software version 9.3 (SAS, Cary, NC). All $p$-values are two sided.

\section{Results}

Of the 2758 individuals recruited during the study, 906 (33\%) were female, $1683(61 \%)$ were Caucasian and the median age at baseline was 37 (interquartile range [IQR]: 29-43) years. The median duration under follow-up was 64 months (IQR: 23 -106). Over the course of the study, 1524 (55\%) participants reported some participation in a methadone treatment program.

Baseline characteristics of the study participants, stratified by recent incarceration, are shown in Table 1. As shown, 381 (14\%) participants reported incarceration in the past six months at baseline. Younger age, at least daily injection heroin use, at least daily crack smoking and currently living in unstable housing were significantly associated with recent incarceration $(p<0.05)$.

The unadjusted and adjusted results of the GEE analyses examining the associations between recent incarceration and participation in the methadone treatment program are shown in Table 2. As shown in the unadjusted analyses, being recently incarcerated was associated with lower odds of participating in the methadone treatment program (Odds Ratio $=0.66,95 \%$ confidence interval $[\mathrm{CI}]: 0.62-0.71$ ). Additionally, in the bivariate analyses, older age, female gender, Caucasian ethnicity, at least daily crack smoking and HIV positive status were positively associated with methadone treatment, while daily injection heroin use, daily injection cocaine use, sex work involvement and unstable housing were negatively associated with this outcome ( $p<0.05)$. In the multivariate GEE analysis, adjusting for age, female gender, Caucasian ethnicity and at least daily injection heroin use, recent incarceration remained independently associated with lower odds of using methadone treatment (Adjusted Odds Ratio $=0.87,95 \%$ CI: $0.81-0.93$ ).

\section{Discussion}

The present study demonstrates an independent association between incarceration and a lower likelihood of methadone use among a group of injection drug users. This cohort was followed in a setting with well-developed methadone programs where methadone is both provided through a network of community pharmacies as well as available within local correctional systems.

Untreated heroin use has been linked to crime and increased contact with the criminal justice system (Bukten et al., 2012; Oliver et al., 2010). As such, correctional facilities are a logical setting for the implementation of proven treatment strategies. Methadone maintenance therapy certainly meets this criterion, the benefits of which have been shown in several randomized controlled trials comparing methadone initiation while incarcerated to usual care (Kinlock, Gordon, Schwartz, Fitzgerald, \& O'Grady, 2009; McKenzie et al., 2012). 
While previous articles have sought to outline the barriers to offering addiction treatment in prison and strategies for implementing effective programs, there has not been a clear description of the association between incarceration and methadone maintenance therapy. Other studies have looked at the effect of treatment on incarceration rates, but have not explored the impact of incarceration on treatment in a quantitative fashion (Reisinger et al., 2009; Werb et al., 2008). The present study was able to delineate this relationship in a large and long-running cohort of individuals who use drugs recruited from community settings.

In an era where law enforcement continues to be the dominant strategy for dealing with individuals with addiction issues, these results pose a challenge (Werb et al., 2013). Specifically, the present study suggests that incarceration of individuals with substance use disorders, particularly opioid addiction, reduces their chances of engaging in effective treatment. What was once considered a solution to a problem - preventing drug-addicted persons from accessing drugs through incarceration - may in fact be achieving the opposite. Regardless of the policy goals, our study adds to the growing weight of evidence suggesting that the criminal justice system is a barrier to individuals with substance use disorders from accessing needed health programs and therapies. In addition, our findings should be seen within the context of international treaties and the laws of many jurisdictions including our own that incarcerated individuals have the right to medical care equivalent to that available in the community.

Limitations of this study include the retrospective nature of the analysis, the reliance on patient self-report, and the possibility of unmeasured confounding factors. The large number of longitudinally followed participants adds to the strength of the association; however, causation cannot be inferred. Likewise, explanations for the association could include factors beyond the scope of this study. For example, attitudes and stigma around methadone maintenance may contribute to poorer uptake of treatment in the prison setting, especially with the decreased privacy surrounding medical care. Incarcerated individuals may feel threatened or stigmatized as a drug addict. Finally, there is the possibility that the sample is not representative of the studied population.

\section{Conclusions}

In summary, incarceration was found to negatively impact participation in methadone maintenance treatment among a large cohort of injection drug users. This association was robust after accounting for confounding factors through multivariate analysis. Methadone maintenance is a life-saving therapy with proven benefit in high-risk populations such as the current study sample. Efforts should be increased to make treatment more available to incarcerated individuals and those at risk of incarceration in light of the present findings.

\section{Acknowledgements}

The authors thank the study participants for their contribution to the research, as well as current and past researchers and staff. The study was supported by the US National Institutes of Health (VIDUS: R01DA011591, ACCESS: R01DA021525). This research was undertaken, in part, thanks to funding from the Canada Research Chairs program through a Tier 1 Canada Research Chair in Inner City Medicine which supports Dr. Evan Wood. Dr. Milloy is supported in part by the National Institutes of Health (R01 DA021525). Dr. Hayashi is supported by the Canadian Institutes of Health Research. 


\section{References}

Bukten A, Skurtveit S, Gossop M, Waal H, Stangeland P, Havnes I, Clausen T. Engagement with opioid maintenance treatment and reductions in crime: a longitudinal national cohort study. Addiction. 2012; 107(2):393-399. [PubMed: 21883606]

Bukten A, Skurtveit S, Stangeland P, Gossop M, Willersrud AB, Waal H, Clausen T. Criminal convictions among dependent heroin users during a 3-year period prior to opioid maintenance treatment: a longitudinal national cohort study. J Subst Abuse Treat. 2011; 41(4):407-414. [PubMed: 21839605]

Callon C, Wood E, Marsh D, Li K, Montaner J, Kerr T. Barriers and facilitators to methadone maintenance therapy use among illicit opiate injection drug users in Vancouver. J Opioid Manag. 2006; 2(1):35-41. [PubMed: 17319116]

Fischer B, Jones W, Rehm J. High correlations between levels of consumption and mortality related to strong prescription opioid analgesics in British Columbia and Ontario, 2005-2009.

Pharmacoepidemiol Drug Saf. 2013; 22(4):438-442. [PubMed: 23319301]

Hedrich D, Alves P, Farrell M, Stover H, Moller L, Mayet S. The effectiveness of opioid maintenance treatment in prison settings: a systematic review. Addiction. 2012; 107(3):501-517. [PubMed: 21955033]

Herget G. Methadone and buprenorphine added to the WHO list of essential medicines. HIV AIDS Policy Law Rev. 2005; 10(3):23-24. [PubMed: 16544403]

Kinlock TW, Gordon MS, Schwartz RP, Fitzgerald TT, O'Grady KE. A randomized clinical trial of methadone maintenance for prisoners: results at 12 months postrelease. J Subst Abuse Treat. 2009; 37(3):277-285. [PubMed: 19339140]

Liange KY, Zeger SL. Longitudinal data analysis using generalized linear models. Biometrika. 1986; 73(1):13-22.

MacArthur GJ, Minozzi S, Martin N, Vickerman P, Deren S, Bruneau J, Hickman M. Opiate substitution treatment and HIV transmission in people who inject drugs: systematic review and meta-analysis. Bmj. 2012; 345:e5945. [PubMed: 23038795]

Maldonado G, Greenland S. Simulation study of confounder-selection strategies. Am J Epidemiol. 1993; 138(11):923-936. [PubMed: 8256780]

Mattick RP, Breen C, Kimber J, Davoli M. Methadone maintenance therapy versus no opioid replacement therapy for opioid dependence. Cochrane Database Syst Rev(3). 2009:Cd002209.

McKenzie M, Zaller N, Dickman SL, Green TC, Parihk A, Friedmann PD, Rich JD. A randomized trial of methadone initiation prior to release from incarceration. Subst Abus. 2012; 33(1):19-29. [PubMed: 22263710]

Miller CL, Johnston C, Spittal PM, Li K, Laliberte N, Montaner JS, Schechter MT. Opportunities for prevention: Hepatitis $\mathrm{C}$ prevalence and incidence in a cohort of young injection drug users. Hepatology. 2002; 36(3):737-742. [PubMed: 12198668]

Oliver P, Keen J, Rowse G, Ewins E, Griffiths L, Mathers N. The effect of time spent in treatment and dropout status on rates of convictions, cautions and imprisonment over 5 years in a primary careled methadone maintenance service. Addiction. 2010; 105(4):732-739. [PubMed: 20403022]

Reisinger HS, Schwartz RP, Mitchell SG, Peterson JA, Kelly SM, O'Grady KE, Agar MH. Premature discharge from methadone treatment: patient perspectives. J Psychoactive Drugs. 2009; 41(3): 285-296. [PubMed: 19999682]

Spittal PM, Craib KJ, Wood E, Laliberte N, Li K, Tyndall MW, Schechter MT. Risk factors for elevated HIV incidence rates among female injection drug users in Vancouver. Cmaj. 2002; 166(7):894-899. [PubMed: 11949985]

Tyndall MW, Currie S, Spittal P, Li K, Wood E, O'Shaughnessy MV, Schechter MT. Intensive injection cocaine use as the primary risk factor in the Vancouver HIV-1 epidemic. Aids. 2003; 17(6):887-893. [PubMed: 12660536]

Werb D, Buxton J, Shoveller J, Richardson C, Rowell G, Wood E. Interventions to prevent the initiation of injection drug use: a systematic review. Drug Alcohol Depend. 2013; 133(2):669-676. [PubMed: 24055187] 
Werb D, Kerr T, Marsh D, Li K, Montaner J, Wood E. Effect of methadone treatment on incarceration rates among injection drug users. Eur Addict Res. 2008; 14(3):143-149. [PubMed: 18552490]

Wolfe D, Carrieri MP, Shepard D. Treatment and care for injecting drug users with HIV infection: a review of barriers and ways forward. Lancet. 2010; 376(9738):355-366. [PubMed: 20650513]

Wood E, Kerr T, Spittal PM, Li K, Small W, Tyndall MW, Schechter MT. The potential public health and community impacts of safer injecting facilities: evidence from a cohort of injection drug users. J Acquir Immune Defic Syndr. 2003; 32(1):2-8. [PubMed: 12514408] 


\section{Highlights}

- Opioid addiction is associated with incarceration and severe health consequences

- Methadone maintenance therapy is the standard of care for opioid addiction.

- Recent incarceration decreases the likelihood of being on methadone. 


\section{Table 1}

Characteristics of study sample at baseline, stratified by incarceration experienced in the past 6 months $(\mathrm{N}=$ 2758).

\begin{tabular}{|c|c|c|c|}
\hline Characteristic & $\begin{array}{c}\text { No Incarceration }{ }^{\dagger} \\
2377(\mathbf{8 6 \%})\end{array}$ & $\begin{array}{c}\text { Incarceration } \\
\mathbf{3 8 1}(\mathbf{1 4 \%})\end{array}$ & $p$-value ${ }^{*}$ \\
\hline \multicolumn{4}{|l|}{ Age } \\
\hline Median & 37 & 36 & 0.002 \\
\hline IQR & $29-44$ & $28-41$ & \\
\hline \multicolumn{4}{|l|}{ Female gender } \\
\hline No & $1585(67)$ & $267(70)$ & 0.190 \\
\hline Yes & $792(33)$ & $114(30)$ & \\
\hline \multicolumn{4}{|l|}{ Caucasian } \\
\hline No & $925(39)$ & $150(39)$ & 0.866 \\
\hline Yes & $1452(61)$ & $231(61)$ & \\
\hline \multicolumn{4}{|c|}{ Injection heroin use ${ }^{\dagger}$} \\
\hline$<$ Daily & $1558(66)$ & $188(49)$ & $<0.001$ \\
\hline$\geq$ Daily & $819(34)$ & $193(51)$ & \\
\hline \multicolumn{4}{|c|}{ Injection cocaine use ${ }^{\dagger}$} \\
\hline$<$ Daily & $1693(71)$ & $269(71)$ & 0.804 \\
\hline$\geq$ Daily & $684(29)$ & $112(29)$ & \\
\hline \multicolumn{4}{|c|}{ Crack cocaine smoking ${ }^{\dagger}$} \\
\hline$<$ Daily & $1847(78)$ & $237(62)$ & $<0.001$ \\
\hline$\geq$ Daily & $530(22)$ & $144(38)$ & \\
\hline \multicolumn{4}{|l|}{ HIV positive } \\
\hline No & $1661(70)$ & $260(68)$ & 0.519 \\
\hline Yes & $716(30)$ & $121(32)$ & \\
\hline \multicolumn{4}{|c|}{ Sex trade involvement ${ }^{\dagger}$} \\
\hline No & $1841(77)$ & $297(78)$ & 0.827 \\
\hline Yes & $536(23)$ & $84(22)$ & \\
\hline \multicolumn{4}{|c|}{ Unstable housing $\neq$} \\
\hline No & $731(31)$ & $76(20)$ & $<0.001$ \\
\hline Yes & $1646(69)$ & $305(80)$ & \\
\hline \multicolumn{4}{|c|}{ Methadone treatment ${ }^{\dagger}$} \\
\hline No & $1822(77)$ & $297(78)$ & 0.576 \\
\hline Yes & $555(23)$ & $84(22)$ & \\
\hline
\end{tabular}

* Results based on the Pearson's Chi-square test for categorical variables and Mann-Whitney test for continuous variables.

${ }^{\dagger}$ Denotes activities in the past 6 months.

Fenotes current activities. 


\section{Table 2}

Bivariate and multivariate $\mathrm{GEE}^{*}$ analyses of factors associated with participation in a methadone treatment program $^{\dagger}$ among study participants $(\mathrm{N}=2758)$.

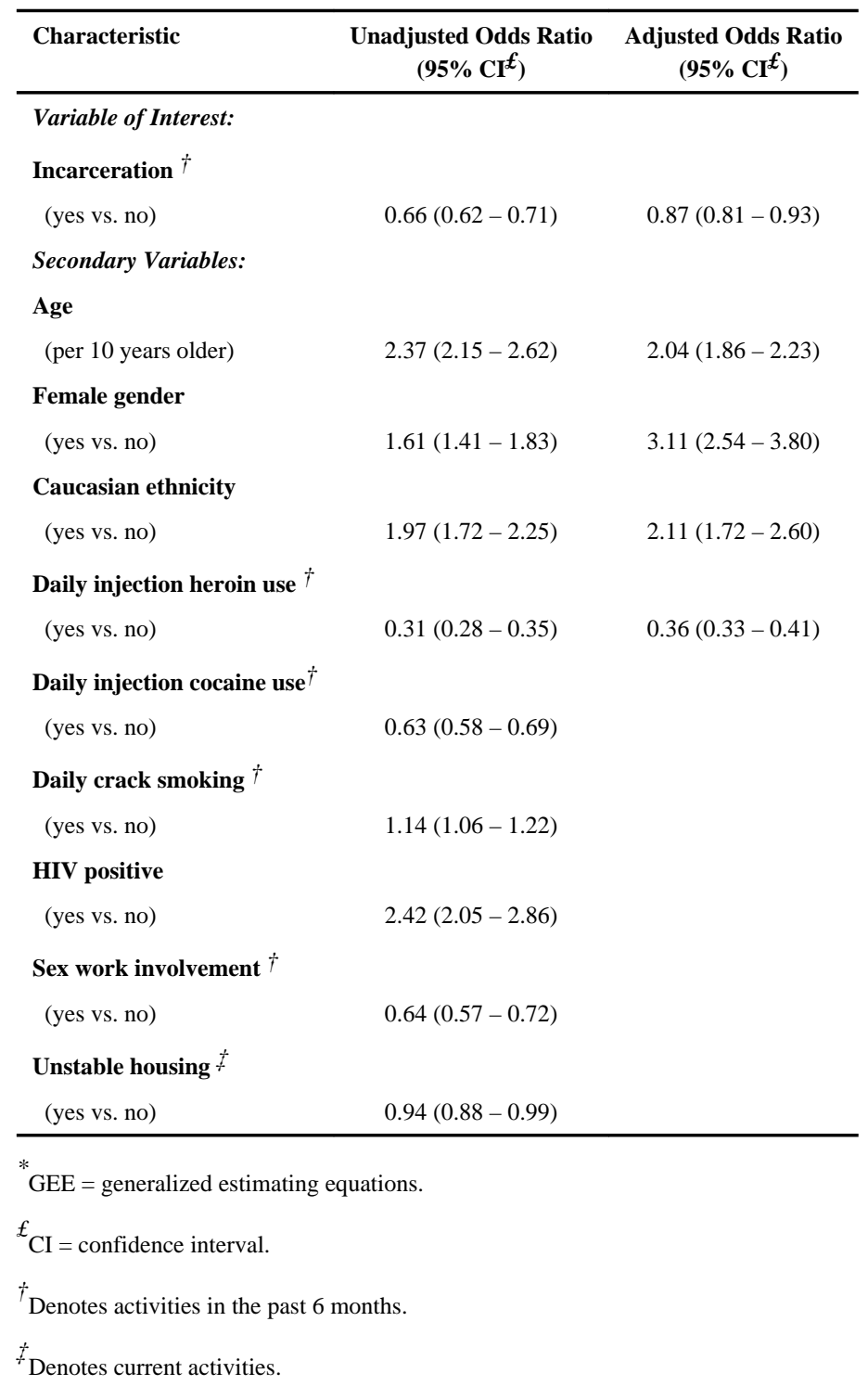

